\title{
Theoretical Profiles for the Evaluation of Insider Trading in a Functional Model of Financial Instruments Market
}

\author{
Paola Fandella ${ }^{1}$ \\ ${ }^{1}$ Università Cattolica del Sacro Cuore, Italy \\ Correspondence: Paola Fandella, Università Cattolica del Sacro Cuore, Italy.
}

Received: November 15, 2017

Accepted: December 5, 2017

Online Published: December 13, 2017

doi:10.5430/ijba.v9n1p1

URL: https://doi.org/10.5430/ijba.v9n1p1

\begin{abstract}
The analysis is based on the premise that the capital market is characterized by weak forms of risk management, to be intended, in this case, as risk of information asymmetry as well as operational inefficiency, as there are no hedging schemes to prevent external actions and internal mechanisms are not inspired by adequate transparency principles.

After a critical review of the theoretical effects of insider trading, starting with a market equilibrium assessment, this analysis seeks to demonstrate the absence of any positive effect linked to insider trading in relation to any type of variable and for any model of the securities market.

Starting from the assumption that the negative trading activity of insiders manifests in any securities market structure, it has been shown that an operating model characterized by the presence of professional operators appears to be more capable of opposing a significant barrier to the entry of insiders.

On the other hand, it has also been shown that the presence of professional operators cannot act alone and it may also lose action incisiveness and even cause informative viscosity effect, when such professional or institutional operators are directly involved in privatization operations.
\end{abstract}

Keywords: insider trading, information efficiency, financial market, professional operators, privatization policy

\section{Introduction}

The reform processes, in a functional and structural perspective, that the financial markets are typically undergoing in order to respond to the stances of globalisation repropose the urgency both to further analyse insider trading also from a theoretical point of view, and, above all, to provide a concrete assessment thereof with respect to the current legislative framework that describes the phenomenon and the resulting disciplinary actions as dictated by the EU directives and the related implementing regulations (Note 1).

This urgency is supported by the need to set up a structural and functional model of securities market capable of preventing, or at least limiting, the disturbing factors induced by the variable under investigation and affecting the overall performance of the market itself.

In effect, the problem of «insider» trading becomes relevant as it is characterised by a totally unusual financial utility function regarding the information cost structure, which is virtually null for those who put insider trading into action. Moreover, insider trading should be considered stochastic both in terms of the timing of its action and its implementation modes.

The consequence is therefore the need to explicitate clear institutional barriers and ad hoc professional (operational) rules designed to codify trading modes based on the principle of disclosure, or of total transparency, for the benefit of each operator.

Given this introduction, the analysis enables us also to demonstrate why the doctrine of this subject does not address univocally the definition of a clear relationship between insider operations and the capital market, admitting almost implicitly the existence of an evaluation gap between the theoretical definition of the factor under study and empirical evidence in the trading market itself. The evaluation gap presents itself as a management gap issue, that is, a risk management issue - to be intended, in this case, as a risk of information inefficiency as well as operational ineffectiveness - according to coverage forms designed to prevent external actions and / or contain internal 
mechanisms that could entail behaviours not inspired by adequate transparency principles.

\section{Verification of Theoretical Approaches Aimed at Explaining the Incidence of Insider Trading on Economic Efficiency and Market Equilibrium}

In order to better explain the possible strategies to evaluate and control insider trading in a management gap perspective, that is, assuming as necessary an adequate coverage of market imperfections (for any degree of inefficiency that can be associated with a specific model of capital market structure), it is key to verify the main theoretical contributions in which the phenomenon in question has been studied so far.

We have already mentioned a substantial indefiniteness of the phenomenon - especially in terms of processes of origin, activation timing and related incisiveness of its action strategy - which leaves unsolved a theoretical problem of ambivalence of the insider effect in relation to performance, under the dual profile of economic efficiency variation and overall capital market equilibrium.

The doctrinal approach to insider trading is substantially - and necessarily - linked to the theory of capital market efficiency as also to the impossibility of verifying equilibrium models capable of ensuring, at any time, the balance between companies' financing needs and demand for financial investments to maximise marginal utility, while at the same time providing for positive revenues consistent with the expectations formulated by the market itself.

This impossibility seems to be mainly due to two sets of factors acting in a complementary way. They distinguish, on the one hand, a number of financial utility functions of the subjects operating in the securities market, albeit for a variety of reasons, which is recognisable in greater or lesser aversion to risk in connection with their specific capacity to decode market expectations; and on the other, the actual development of the information dynamics, whether it is intended as the process of origin of the information or its transmission in the trading process (Grossmann \& Stiglitz, 1980).

This implies, however, that any structural market model that discloses relative efficiency should contribute, in brief, to configuring functions aimed at:

— minimising costs of purchasing and / or selling operations of financial instruments;

— minimising costs of information access and / or delivery on the part of issuing companies;

- minimising the time gap in the transmission of information between subjects contributing to defining the activity of the capital market;

- developing adequate structures, mechanisms and operational tools capable of facilitating operations of financial instruments based on capital markets.

It goes without saying that these functions must be understood as mutually correlated processes, rather than as intermediate objectives, and that only together can they increase the degree of efficiency of the overall market model.

In this context, the process contributing to the definition of the incidence of insider trading in a given structural capital market model clashes, at a theoretical level, with two variables likely to express opposite market consequences, and the combination of which, thus, brings in strong indefiniteness in the evaluation, as well as in the development, of the action of the insiders themselves.

With respect to the so-called «economic theories» which take the ethical and legal aspects of insider trading as given and which, on the other hand, evaluate its effects on market mechanisms and on operators' advantage, this paper makes reference to the following circumstances:

- First of all, insiders necessarily introduce relevant information for the market, in the absence of which their own strategy of action would be non-existent;

- Secondly, insider traders in any case implement their own financial function utility converging towards overall market trading.

The exasperation of one or the other of the above-mentioned circumstances leads, also at a theoretical level, to interpretative positions which are either wholly favourable to insider trading or, at most, uncertain on its impact in the market, with the consequent tarnishing, in our opinion, of the objective requirements of market information efficiency and operational effectiveness, and which, in any case, presuppose a linearity of action for individual subjects, despite diversity in expectations and financial utility functions.

\section{Limits to the Theories Regarding the Inadmissibility of Insider Trading}

In the interpretative exasperation of a unilateral effect of insider trading action, an extreme position arrives to sustain 
a positive relationship between insider trading and market performance (Manne, 1966), arguing that in any case no one would be damaged by insider trading while someone might even benefit from it.

In particular, this position bases its assertion on essentially three points:

1. Any factor that causes a variation in the stock price and brings it closer to its real intrinsic value results in an improvement of resources allocation;

2. No operator loses by negotiating with insider traders, because all those who have sold or purchased securities from them, even taking losses (either in an absolute sense or in terms of lower earnings), would in any case have made operations.

The insider trader is essentially seen as a market operator who has to act according to the market rules searching for counterparts, which are always free to accept the exchange or not;

3. Corporate executives are also encouraged to innovate since they can take positions whenever there is a variation in the stock value.

Ultimately, this approach arrives to support the admissibility of insider trading operations in the market, limiting the significance of their incidence to the first element which defines the insider operation, that is, the fact that subsequent trading can be based only on a relevant piece of information, even at the expenses of the implementation of the insider strategy itself, as better analysed below.

In practice, the doctrine in question arrives to ignore or, at least, minimise the condition of imbalance highlighted by the theory of information asymmetries (Leland \& Pyle, 1977), limiting the benefit of the operating revenue that the insider trader would obtain from the market to a marginal factor that can be absorbed by the market itself, in any case favoured by the distribution effect of the information introduced through this channel.

Under this hypothesis, in fact, one simplistically ends up admitting a result of overall market readjustment in the algebraic sum of losses and revenues, thus completely avoiding the implications that the insider phenomenon projects on the brokerage function, which consists, by definition, in actual continuity in the medium and long term.

This also means admitting a substantial lack of attention towards the effects of variation in the degrees of risk aversion of single non-insider operators, towards consequent redefinitions of the respective financial utility functions, and towards the impact of the insider on the degree of market thinness, etc.

However, the informative acceleration effect that the theory under discussion recognises in the insider action (without prejudice to the finding that the potential counterparts remain free to accept or not the specific trading in question) basically neglects the consideration of a stage equally important as information disclosure to the market. This stage identifies with the transparency requirements inherent in both the standardised forms of information codification, and in the disclosure process itself that could be defined «internal» to each potential operator as a process of understanding and, therefore, of evaluation of the information being observed.

While it is true that, negotiating with an insider, the counterpart always has the freedom to conduct or abandon the negotiation, it is equally true that any action taken under the conditions of imbalance mentioned above is necessarily carried out in terms of agency or absolute dominance in favour of the insider.

In addition, it remains to be verified whether the information object of the particular form of trading under consideration can still be defined as «evident» even by accepting the «marginal» gap of gain for the insider; It will in effect be demonstrated below that the insider intends to dilute over time the complete introduction of the information to the market as the full manifestation of the information tends to coincide with the practical nullification, for the insider operator, of the certainty of acquisition of any kind of differential gain.

In other terms, insiders find themselves in the position to manage an arbitrage situation on the same stock and on the same market, with the possibility of countering any rebalancing mechanism until the market has fully appreciated the value of the information that originated the trading.

Additionally, it is quite credible to assume that the insiders finalise and, above all, circumscribe their operator activity to the use of the confidential information they hold (Note 2). Therefore, it is quite obvious that in this case also the hypothesis of safeguarding the overall equilibrium of the market as a result of the marginal costs and revenues «game» would cease to be applicable. In the market portfolio, in fact, at the end of the operation, only marginal losses would probably remain to be offset, given that revenues directly attributable to insider action are very unlikely to be reinvested.

It is illuminating, in this regard, to consider the insider-information relationship so as to capture the elements of 
stochasticity of the insider action which can be primarily seen in the time variable that affects both the insider trader's strategy and, more broadly, the market.

In the former case, in fact, the operator does not know exactly when he will be able to act «as an insider»; in the latter, on the contrary, the market does not know when the insider will decide to enter.

In such a condition, the informational asymmetry effect differs, on a theoretical level, from the effect originated by the «traditional» process characterising the issuer-market relationship; and this also regardless of the investigation of the problem of substitution between the issuer and the insider, to focus instead on the way information is transmitted to the market.

The insider-information relationship - however it is considered - can in effect never be balanced, since even if we admitted the benefits of the acceleration effect induced by the information that insiders transmit, these end up being in the lucrative condition of not having to bear any costs of market access (such as the costs of information preparation always pertaining to each issuer) or the costs of the failure of the operation, in the event it involves, for example, a request for funds to the market or simply statutory modifications.

Basically, in all the options proposed, the games of the market will never be a fair game.

Even from a different perspective, the theoretical strand under consideration can lead to passively acquiring and implicitly accepting insider trading, inducing or simply tolerating viscous elements in the correlation between the variables that define the structure of the capital market as a whole, and in any case such to make a radical counter-attack to the phenomenon in question more difficult.

After all, also at an institutional level (Portale, 1989) - even not considering the specific contents of the regulations the more financially advanced countries are experiencing a difficulty in adjusting operations to satisfactory levels of effective disclosure, a circumstance which is also confirmed by the fact that discipline on the prevention and repression of insider trading seems to be defined by particular forms in each country.

In particular, an absolute and effective repressive power has been entrusted to the SEC in the United States where, practically, the Authority uses a flexible structure to control «,., any person, any securities, any information...» in order to be able to determine, case by case, the most appropriate action to prevent or repress insider trading.

In the wake of the US system, but, at least for the moment, with less effectiveness at a practical level, the French system - the first in Europe to adopt an ad hoc legislation in the subject-matter under discussion (1967) - defines more synthetically the nature of confidential information, the insider offense case, also including punishment for indirect exploitation through communication of a confidential piece of information to a third party (tipping), in the attempt, above all, to simplify - compared to the SEC - the structure of the controls without losing effect in carrying them out.

More self-discipline is found in the experience of the British system where gentlemen agreements are accompanied by exogenous regulations (first of all the City Code on take-overs and acquisitions of 1964).

This form of insider risk management by external authorities and endogenous market bodies is also reflected in the German system where, however, the power of self-control is virtually absolute, given that the legislative power only holds the competence to define the notion of privileged information while the task to oversee the forms of insider trading has been entrusted to the capital market operators' associations.

\section{Profiles of Theoretical and Interpretative Ambiguity of the Insider Phenomenon}

A more problematic dimension of this phenomenon is proposed by another theoretical strand (King \& Roell, 1988) which, starting from the analysis of the financial utility function of the insider, ends up confirming what has already been refuted in reference to the previous theses, namely that the trading «games» promoted by insiders can only be inevitably unfair for the rest of the market.

The focus of this theory is on the insider-market relationship in order to extrapolate the different degrees of reaction to the different utility classes attributable to individual market players.

Specifically, in this respect, the theory highlights the position of particular disadvantage that insider trading gives to market makers, that is, those who enter into primary and direct negotiations with insider operators, although this role has the possibility of transferring part of the losses suffered to other categories of operators widening the gap between buying and selling prices (bid-ask spread).

In this sense, the effect of insider trading is said to be equivalent to an «investment tax» paid by all traders that ends up triggering a redistribution of revenues in favour of the insiders. 
The theoretical approach under consideration is based on two distinctive key assumptions.

Firstly, the substantial passivity to react attributed to the market maker and, therefore, the absolute asymmetry recognised in favour of the insider.

This passivity or dependence of the professional intermediary, whom the market entrusts with the task of ensuring continuous trading based on rules of transparency, thickness, liquidity, etc., is basically justified in the absolute unpredictability of the temporal strategy of the use of confidential information in the hands of the insider.

Secondly, the doctrine in question also distinguishes between the «balance effect» and the «efficiency effect» of the insider. And while this doctrine recognises, with regard to the «balance effect», a negative trend, which is actualised by the «tax» taken on by the market maker and redistributed to the whole market, it instead attributes to the «efficiency effect» an almost stand-alone role with respect to the disequilibrium effect, as if it were possible to abstract, in the information integration function, the problem of the significance of information (in this case relevant and private) from that of the effectiveness of the transmission itself.

Even though this abstraction can be attributed to the concept of strong market efficiency (Fama, 1976) - according to which all public and private information is fully and timely incorporated by the market even when it is known only by a small number of people -, in our view it entails a reappraisal of the information integration problem since it completely ignores the very relevant aspect of the way information is transmitted.

In this case, in fact, it is exactly Fama's efficient capital market hypothesis that admits a positive market effect of the insider action through the extreme reduction of the limited number of persons that access the information known to insiders only.

The theory under consideration acknowledges in fact that insider-driven trading improves efficiency in pricing, and that the possibility to carry out operations on the basis of confidential information allows those involved to sell (and to buy, in the opposite case) more quickly than the other operators in case news on company's performance is negative, thus anticipating the incentive effect for the executives of the company to try to re-establish its fate.

This implies, however, the irrelevance of the weighting of the actual degree of risk effects on the financial investment for the various classes of investors compared to the possibility of an incentive for executives.

In other terms, as we have seen, in the insider operation admissibility theory the cost for the market has been given for certain - a cost that, after all, in insider operations, may only vary with positive growth rates compared to the depth and thickness of the action itself, increasing, in absolute terms, the degree of aversion to financial risk. On the other hand, the hypothesis of inducing an incentive role in management and, in particular, the likelihood to successfully restructure the company subject to the insider operation are both uncertain (as well as costly), and, in any case, they do not exclude the disinvestment of certain stocks by the market, which has become aware of its delay compared to the insider action.

\section{Theoretical Limits to Insider Trading Admissibility on the Basis of Market Balance Analysis}

The variability of the insider's effects, if referred to the different counterpart relationships that can be assumed to be present in the market and observed with respect to efficiency and equilibrium results, is proposed in joint form only in the most recent doctrinal interpretation (Leland, 1990).

This approach, by analysing the impact of insider trading on economic efficiency and overall balance, and by trying to measure the gains and losses of the single operators, attempts to establish the overall repercussion effect of insider trading.

According to the theoretical elaborations set out above, whether insider trading is acceptable or not seems to mark down the informative effect with that of market balance.

In general, the - inadequate, as has been seen - hypothesis of a positive effect of information acceleration that would result from insider trading leads to the following conclusions:

1. Insider trading enables the reduction of risks and an increase in performances because securities price values reflect better conditions;

2. As a result of the reduction of risks, goods prices tend to be higher, thus boosting investment.

On the other hand, perspectives contrary to these positive feedbacks deriving from insider operations are devised in the following points:

1. Investments in securities are reduced because the market moves under iniquity conditions induced by insider 
action, and this leads to lower prices;

2. Security prices become much more volatile, and this damages, primarily, private investors;

3. The overall market appears to be less liquid.

As we have seen, balancing towards one position or the other has not been unanimously accepted by the doctrine, causing, in our view, a slowdown in growth of the overall trading capacity of any structural market model.

Leland's model proposes, instead, an investigation of the insider effect starting from the analysis of market balance, and deducting the derived information performance from the single balance relationships (for example, the issuer and insider relationship) in order to derive and measure the incidence, or weight, of the insider effect on the overall market.

Starting from the assumption of an initial equilibrium model with rational expectations - also referred to as the $R E E$ (Rational Expectations Equilibrium) - that makes equity demand and offer equal for every possible stochastic variable potentially present in the market (whether it is an insider action or an action of the so-called «uninformed» operators who intervene in the market without an established strategy), any price formulated in the market is found to be significant of the encounter of (equilibrium) expectations between counterparts.

This equilibrium is grounded in two basic assumptions:

1. First of all, that the rational nature of expectations implies, for each operator, a logic of intervention based on a particular investment and / or disinvestment strategy, and therefore that operators without such a strategy, or solely driven by profit and liquidity requirements, represent an intrinsic "noise" in the market;

2. Secondly, that privileged information reaches the market only through the insiders, namely that there already exists a system of due information which de facto represents the minimum information integration relationship in the equilibrium of the parties involved in the securities market operations. These «parties», as we know, are divided into: issuers, intermediaries (market makers, dealers and brokers), professional investors, decoding investors, private investors and insiders.

This allows us to define the features of the different relationships between the insider trading phenomenon and each observed variable.

This model also implies the possibility of explicating the probable paths of action of the phenomenon under consideration by combining feasible sets of relationships that can be detected between the examined variables.

This analysis contributes to delineating and attesting the likelihood of occurrence and frequency of adverse effects on the performance of the identified relationships for any structural market model considered. It also allows to extrapolate valuation criteria for the insider phenomenon in the light of the characteristics of the variables mentioned above with reference to the Italian securities market.

\section{The Variables That Characterise Market Performance and the Degree of Exposure to the Phenomenon of Insider Trading}

The analysis of the variables that characterise the performance of the securities market is presented in an outline that aims to identify the points of greater exposure and sensitivity to insider trading events.

As said, this analysis implies the concept of equilibrium and information efficiency as performance objectives of the market integration model (Fusconi, 1991), and it enhances the investigation of exposure and / or dependence degrees in relation to insider trading events for each examined variable. Moreover, this study enables attesting the equilibrium and information efficiency that the market shows, which it must contribute to increasing even for the sole purpose of implementing a relative performance function.

From this perspective, insider trading necessarily becomes an independent variable as it is not foreseen in the market portfolio and, above all, it is not determinable in its manifestations or, more generally, in its operations; moreover, it is the only variable to have privileged information.

Inevitably, the approach that we intend to follow does not refrain from considering as primary, by degree of exposure to the risk of insider trading, the two dominant variables of the integration process, namely the issuer segment and the investors' portfolio.

With respect to the relationship between the issuer segment and the insider trader, the attribution of a first degree, or direct, qualification to the above mentioned relationship seems quite obvious.

Insider trading is indeed generated by the issuer segment, to the point that it can be asserted that only in the specific 
relation issuer-insider emerges a reverse relationship of dependence with respect to the origin of the phenomenon under investigation, since the issuer, whatever it is, always keeps the exclusivity to generate information by type, value and time.

Likewise, it goes without saying that the reverse relationship of dependence arises and concludes in the information creation phase, and that, therefore, insider trading also takes from it the reason to assert its independence compared to the market in general, being this phenomenon essentially projected to become an atypical user of the information produced by the issuer.

Therefore, from a structural point of view, there are no market barriers to prevent this phenomenon. In this respect, the only constraints on insider action are to be traced back to forms of surveillance entrusted to strategic prevention action, set up at microeconomic level by the single issuers of information.

The accomplishment of the analysis of the insider-issuer relationship finds explicit expression also in the effects that the use of information by the insider causes to the market.

In this respect, the relationship can be explained indirectly, that is, by introducing the nature of the second most important relationship, namely the one between insiders and the (portfolio of) investors.

The importance of this relationship is equally intuitive to measure the impact of the insider effect on the market performance function, as it directly pertains to the trading part of information integration. In other words, the creation of relevant information in itself is a necessary but not sufficient requirement to trigger a market information event. In fact, this is manifested only through informational integration, that is, the transmission of information in the context of primary or secondary negotiability.

It goes without saying that the process of integration implies two opposing poles to bring closer: those who create the information, and those receiving it. If, in principle, these poles are represented by the issuer and the investors' portfolio respectively, such clarity of positions may also be flawed by insider operations.

In this sense, it has already been seen that the insider can replace the issuer not in the phase of information creation but when this information is disclosed to the market.

On the other hand, the nature of the second pole of integration - which, as has been said, can be represented by the investors' portfolio - takes on an equal importance.

In effect, this variable represents the receiving or beneficiary part of the intervention - and of the information implicit in it - promoted by the insider. However, if, on the one hand, it acts as a passive part during the time of reception of the impulse discretely induced by the insider, or by those who, in any case, propose the information, on the other, it is an active agent in the process of information negotiability, that is, of perception and inclusion of the event in the transaction prices and volumes, in a function that can be hypothesised as continuous.

In identifying the composition of the investors' portfolio for a specific market under consideration, distinguishing by segments of professional, decoding and uninformed operators, a first degree of exposure to insider action can be detected. It is quite probable indeed that the insider action finds a more favourable ground when referred to a portfolio strongly characterised by uninformed operators and, as such, not in the condition to correctly assess the information.

This first observation on the degree of exposure to insider trading also admits a longer-lasting trading penetration effect, and is characterised by higher-density profiles proportional to the degree of scarcity or lack of information decoding ability, and by a similar delay in capturing any deviations produced by the action of the inside (Meulbroek, 1992).

On the other hand, a level of constraint or obstacle to the insider operation - which, however, affects the market operations, particularly in the objective requirement of the degree of thickness of the negotiation - can be observed in the degree of aversion to risk attributable to the so-called "uninformed" investor class which is more subject to insider exposure than other classes.

It is believed, in fact, that the greater the degree of correlation between the congenital lack of information and the degree of risk aversion attributable to the class of investors concerned, the higher the risk of illiquidity likely to occur in the market if the investors themselves, destabilised by insider action, accentuate their aversion to financial investments.

It goes without saying that the highest degree of risk aversion among uninformed operators needs to be counteracted by an equally effective penetration action by the insiders who, in that case, are called to concentrate their efforts in 
assessing the thickness of their own intervention rather than its time interval.

This circumstance is determined not for the effect of the perception of the insider phenomenon or of the information that determines it, but simply because of the costs increase, an opportunity that the uninformed operator has to face more frequently and with a more pronounced incidence, in a market situation virtually lacking an indication of the actual trend of reference.

This ultimately leads to the inevitable departure from the market of this class of operators, which, in turn, will affect the significance of the trading itself, the more the uninformed segment is, as has been said, proportionally relevant within the overall investors portfolio.

But also in this context, if the insiders were able to fully exploit the value of their confidential information before the market, they would remain immune to the shift in the value of exchanges produced by their own operation, which instead would fully impact on the process of continuous trading of the market.

We also want to point out that the effect of depreciating the negotiation value is always and in any case present in the market whenever an insider action infiltrates it, i.e. whether the destabilising action of the operating subject involves a decrease or an increase in the price level. And this is because the effect of departure of the uninformed investors from the equity markets is induced by the perceived inability of inferring - even erroneously - any trend to be able to intervene properly.

In effect, it must be clearly underlined that insider traders are not interested in 'making' the market, and in practice they do not 'make' it; instead, any market drag ends up "disturbing" the insider traders' intervention as it increases the likelihood that other investors may perceive the value of the information held by the insiders.

This leads to the conclusion that, both when information is true and when it is manipulated, the insiders always cause a disturbance factor because only under this condition can they fully pursue their specific purposes.

Ultimately, insider traders are not happy if other traders follow them, and, therefore, they do not have any advantage in showing their action until they have reached the portfolio goal.

Disclosure of information to the market, from an insider trader perspective, becomes explicit when the action is concluded as an effect of «validation» of the adopted trading behaviour and of the acquired result. In other words, if the insiders fall into a bullish perspective, they will reap an advantage in confusing the market until they finish their investment at affordable prices and, therefore, until they trigger a reaction of price rises following their choice of portfolio in order to concretise its revaluation both as asset value in itself and in a profits generation perspective, at prices reflecting the bullish factor induced by the insider action; vice versa, in case the insiders pursue a process of disinvesting their portfolio as a primary action.

Taken in this perspective, therefore, the insider strategy does not seem to leave room for any benevolent interpretations of its effects on market trading. Indeed, also in relation to the first of the identified relationships between the issuer and the insider - it is obvious that insider trading cannot be seen as admissible in terms of positive acceleration of information integration because it rather tends to determine in the market a significant delay in the process of efficient information integration; with the addition of a manifest dystonia also with respect to the strategic time choice of disclosing information formulated or programmed by the issuer.

Moreover, in this perspective, also an analogy of positions between the issuer and the investors is reaffirmed, since the phenomenon in question appears to be an element originally alien to both these market components.

The insider trader and investors portfolio relation, examined so far in the light of the analysis of the insider effects, is also to be compared - always from this perspective - with the two remaining classes of operators previously identified: the so-called information «decoding» investors; and the «informed» investors.

Regarding the relationship with the first category of investors which, according to the classifications, is supposed to be able to decode market movements only ex post, it is reasonable to assume that the action of the insider causes on them effects similar to those already described for the so-called «uninformed» category of investors. And it can be added that, in this case and specifically, the more the insider succeeds in causing disturbance in trading, the more the «decoder» will be penalised compared to the completely uninformed operator.

In fact, it is to be assumed that, while from the class of uninformed operators one can expect a component of irrationality or a not fully reasonable behaviour - that is, a certain degree of irrationality in accessing the market -, this factor fails, or is in any case reduced, when referred to the class of operators able to decode the behaviour of the market inspired by the action of professional operators. 
After all, this stance is inferable considering that the class under investigation admits a minimum level of information which is indeed inferred from market operations (the so-called information trading). In other words, these operators acquire the information without interpreting it independently, but relying on the indications coming from the market itself or from the market makers; it can also be stated that the decoding operators' expectations on the market are adjusted according to the action of the market itself.

Consequently, in the presence of an insider phenomenon, the destabilising impact caused by a non-decipherable action will be so much stronger for the class of investors under consideration, the more susceptible the insider action to be characterised by stochastic factors.

It would be legitimate to expect a reaction of the «decoding» operators to take place and be completed in a shorter time than that, in terms of the degree of time penetration, connected to insider action with respect to the class of the «uninformed» investors. And this is because, as well known, «decoding» operators by definition have the tendency to perfectly aligning their trading choices with those of professional operators, thus implicitly acknowledging the greater ability (likelihood) of the latter to seize and interrupt the insider action.

In this sense, decoding operators are characterised as a class of investors who fully suffers the insider action and who, likewise, entrusts the possibility of transferring the suffered losses completely to another class of operators, namely the professional investors.

Thus, this makes it possible to reiterate that the recovery capacity that can be considered endogenous to the market itself is entrusted to the role of the informed operators, namely the only investors portfolio class with a recognised ability to interpret the information.

It is well known that the institutional investor is actively dedicated to both capturing the time of market information disclosure and understanding correctly the nature and the relevance degree exactly because of its total neutrality to risk.

In this context, the operations of this class of investors are characterised as a real force, endogenous to the market, of potential limitation to insider trading.

It should also be reiterated that this endogenous force or barrier does not act so much on the origin of insider action the issuer - insider relationship is defined, in fact, preliminarily and beyond a market logic, even if it is aimed at a particular market structure (in which the insider agent becomes a trader and, as such, a real disturbance factor in the market itself), but basically explicates itself in the prompt detection of insider action and, therefore, in opposing it and consequently annihilating its value.

This is essentially a de facto expulsion of the insider, as much more immediate and radical as the more professional investors are able to absorb the insiders' competitive advantage - in temporal terms - as well as their qualitative (informative) advantage, avoiding any form of negotiation with them, or because, having perfectly understood the value of confidential information, they are able to negotiate on the basis of the same information quality.

In this sense, also the reverse relationship between market information efficiency and insider operations can be inferred, so that the degree of dominance of the insider will be much more marginal, the more the portfolio of market operators is represented by professional or institutional investors.

The degree of information efficiency, however, is not sufficient to explain the ability to react to the insider phenomenon. In order to evaluate the overall performance of the market, in fact, also the functional effectiveness of the operation structure should be considered, which likewise contributes to refining the pervasive effect or value of information integration.

In particular, in order to explain the pervasiveness value of the information integration function, reference is expressly made to the quality of the brokerage variable (Fusconi, 1991) and to the degree of exposure to insider risk that may be introduced in the market by a particular type of negotiation.

With reference to the structure of different types of brokerage - whether it is pure brokerage (broker) or portfolio management (dealer) - it is to be assumed that the insider relationship basically manifests itself in two points of analysis:

a) The incidence of transaction costs;

b) The degree of competitiveness of the intermediary market itself.

The analysis of the two points identified first requires a distinct evaluation of the incidence of the two variables recalled by them. 
With respect to transaction costs, which may be described as a structural variable or a variable functional to the specific market of reference, it can be said that their impact on the insider operation is negative. If we consider, in fact, that insiders do not necessarily want to manifest their activity in the market (which would damage the uniqueness of their action), they would presumably seek a maximum diversification of their activity through the distribution of their strategy via diversified operations with $n$ intermediaries, being $n$ the optimum number not to reveal their action. This, in other terms, implies:

1. That insiders should be working with a number of intermediaries in order to keep their strategy secret;

2. Moreover, that the relationship between insiders and intermediaries becomes the most critical issue for the insider. In fact, in order to carry out their action, the insiders must entrust themselves to the action of professional operators whose objectives are by definition contrary to the "insider's", since both as dealers and as brokers they essentially contribute to forming the function of market equilibrium in terms of liquidity, negotiability, etc.

If the hypothesis of a collusive equilibrium between insiders and intermediaries is excluded - which in any case should be considered as a pathological market phenomenon, if not only for the fact that the insider has a function of participation in the market which is unique, or in any case non-continuous, while intermediaries must, by definition, operate according to a continuous function -, this leads to the need for insiders to diversify their relationship with a number of intermediaries in order to «delay» the disclosure of their strategy.

This logic is also confirmed in case a strategy of insider action dilution over time is adopted in order to maintain unchanged the anticipated profit (investment) objective.

In this sense, the incidence of transaction costs binds the insider to a trade-off between the number of intermediaries to contact and the operating strategy diversification costs.

Paradoxically, in a theoretical perspective, the insider should be forced to operate only in an efficient market in an absolute sense where, as well known, the absence of transaction costs is assumed: in that case, the multiplication of distribution relationships between insiders and intermediaries - whether they are brokers or dealers - would depend solely on the discretionary assessment on the part of the insiders themselves about the optimal number of operators to refer to in order to achieve, with the highest degree of certainty, the planned result while keeping their strategy hidden to the market.

The evidence of the inadmissibility of the proposed hypothesis - which, however, demonstrates how the absence of transaction costs for insider operations is theoretically sustainable, regardless of the degree of absolute efficiency of the market - is deduced, as stated above, also from the degree of competitiveness among the various intermediaries present in the market.

The greater the number of intermediaries operating in the market, the higher the degree of dilution of insider action, as mentioned above; but the greater also the likelihood that some market players will detect suspicious positions in trading.

In this sense, therefore, the role of the trading intermediary, whether as a broker and / or a dealer, contrasts with the insider's not so much at the information level but in the action of information interpretation that the intermediary takes on in ensuring market trading continuity - since it is known that brokers merely report trading orders to the market and that dealers must necessarily execute contracts at the price they have declared.

It can also be argued that if the intermediaries believe that insider behaviour occurs - regardless of regulatory actions - they could deliberately choose to diverge the value of the spread with respect to the dynamics of the rest of the market (defined by competing dealers), thus not ending the order and signalling to the market the triggering of a potential imbalance factor.

The degree of competitiveness of the intermediation market also helps to explain why the hypothesis that the position of insider be taken on by an intermediary - even if theoretically admissible - does not appear to be acceptable.

This can be demonstrated since the very nature of the intermediary function - which, as recalled above, involves a continuous permanence in the market until the possible physiological depletion of the function itself - heavily clashes against the need and willingness of the insiders to assume an occasional position in the securities market, which can be only explained because of the confidential information they hold.

In this sense, the barrier to insider operations for a negotiating intermediary is always based on the technical continuity of the function performed and on its level of competitiveness.

Both mentioned factors appear to be functional efficiency elements of the securities market, which can therefore also 
affect the determination of the effects of insider action even if not explicitly considered in the analysis models examined so far, including the Leland model.

By analysing the value of insider action with reference to a more technical market variable and one that refers more to the - focused or continuous - negotiation mode in the trading mechanism, some further observations can be deduced.

First, by looking at the variable represented by the type of trading in an absolute sense - that is, abstracting from any structural market model -, it is noted that focused trading seems to be a trading mechanism more suitable to limit insider risk than trading based on continuous auctions.

This is because, as well known, the former is characterised by a type of trading defined both by a temporal specificity in terms of the time spent in trading and by a concentration of exchanges. The same can be said in relation to a greater degree of operational flexibility found in the continuous trading mechanism, which seems to be suitable to favour the dilution effect envisaged in the insider strategy (as stated above, a necessary effect both to limit the risk of disclosure to the market and to keep price fluctuations within a range deemed profitable for the implementation of the strategy itself).

Conversely, concentration binds market reaction to the specific moment of the negotiation with the possibility for insiders to increase the chances of immediately achieving their target for the entire session. From this perspective, the continuous auction, instead, contributes to stimulate market reactivity - since trading information on the screen immediately reflects the values of the agreed contracts - as well as to reduce the pay-off of the insider strategy every time a part of the investment (of the strategy) is agreed at different prices.

Last but not least, continuous trading implies greater precision in determining the entry strategy on the part of the insider, since any proposal entered into the circuit, however executed or not, represents a so-called explicit trading information for the entire market.

Alongside these endogenous mechanisms limiting insider risk exposure, there are the operating limits of the functioning of the trading itself, which, besides providing immediate information on proposals and negotiations by appearing on the screens of each authorised intermediary in real time, also drive price and quantity variation for established percentages (See, for example, the rules established by Consob and Borsa Italiana about the maximum percentages of the difference between theoretical opening price and reference price between a new proposal and the last concluded contract, etc..1).

On the other hand, in relation to the regulation variable, the insider action supports other kinds of limits and relationships.

Without prejudice to the direct and specific regulations (Note 3) which represent the institutional (and exogenous) answer to the phenomenon under investigation, implicit relationships between insider trading and regulation can also be seen in the type of regulation that governs a certain market model.

In other words, it is necessary to detect whether there are other external «forms» limiting the actual trading possibility of the operator - beside the internal barriers that limit insider action, and that can be referred, as already examined, to the presence of institutional investors or to the high degree of competitiveness between intermediaries in the negotiations.

From this point of view, the reference is not so much to the discipline that regulates the minimum level of due information, because the insider information, in itself, is typically independent from any schematisation in the temporal process of presentation (and integration) of information to the market, being subject to undue subtraction from the issuer.

The relationship between the insider and the regulation, intended in general terms, specifically refers instead to the degree of functional efficiency which this (exogenous or endogenous) regulation allows the market to reach, be it a primary or a secondary market.

More specifically, in the primary market, the mechanisms to ensure the correctness of the criteria to submit information and requests in relation to purchases and sales of public bids seem to be subject to a high degree of exposure to insider risk.

The most uncertain component in these processes is the time interval between the date of submission of the bid to the competent authorities and the actual date of approval and offer to the market (cooling period).

The elements that increase the risk of exposure to insider action during this «cooling» period are added to the risks of 
obsolescence of the offer due to changing expectations and market conditions, which the literature has widely debated (Chemmanur, 1989). Last but not least, it must also be considered that if the insider process originates at this stage, the task / risk of the interpretation of information is actually granted, as this is already perfectly prepared for a public offering: the insider, therefore, can act without any risk of interpretation, by simply anticipating the time of the offer to the market.

On the other hand, in the secondary market - still in relation to the primary bid - the official listing time of the securities subject to the bid can be considered as a period of scarce or unmanaged information and operating disclosure that physiologically supports the action of insider trading, defined as an element of disturbance and, above all, one that draws its own advantage from a scarcely transparent process of negotiation.

The «waiting» period between the closing of the bid and the official listing of the stock is limited to the days technically needed to conclude and formalise all transactions (we speak of a one-week maximum deviation).

The institutional aspects here identified make it clear that the process of action of any insider strategy - beyond any sanction discipline - is easier to apply to market structure models that have a poor degree of integration, not only at an informative but also at a functional level.

Any gap in the information integration process, in fact, contributes to determining a dystonia in the continuous trading process, assuming it as a set-up - as seen above - of issuers, investors and intermediaries.

\section{Concluding Remarks}

The critical review of the theoretical effects of insider trading, starting from a market equilibrium assessment to consider the level of information integration, has made it possible to highlight its possible impact on the different variables that contribute to defining any securities market model, as well as, to evaluate its possible variability of incidence depending on actual characterisation.

In this way, we tried to prove that no positive effect seems to be attributable to insider trading in relation to any type of variable and for any model of securities market considered.

In fact, even information integration itself - which, according to some authors, would have a positive effect attributed to the type of trading under discussion - does not occur at all according to market disclosure principles, whose purposes are completely alien to or, better, completely divergent from the insider strategy.

The negative action of insider trading is finally manifested in any securities market structure, although an operating model characterised by a peculiar presence of professional operators has been shown to seem more capable of opposing a significant endogenous and functional, i.e. not dictated by exogenous regulations, barrier.

On the other hand, it has also been demonstrated that this endogenous factor cannot act in an exclusive way, and unconditionally increase its effects. It may, in fact, lose action incisiveness and even cause an informative viscosity effect in the market, in case professional or institutional operators are directly involved in mainly creating privatisation operations.

In the particular case of this bid, this effect could be closely related to the increase of the issuer's risk aversion degree and, hence, to the issuer's degree of dependence on the institutional investors' game to ensure the success of the placement.

The accentuation of this process could even lead to vanquishing any margin of information asymmetry - typical of any bidder and assumed in the market equilibrium function to offset marginal entry costs for the issuer - for the benefit of a single category of investors, with the risk that the latter may intervene in a clearing price manipulation action until they make this price lower than actual market value and their own reserve price.

The likelihood of the occurrence of this hypothesis further contributes to enhance the importance of an overall increase in the performance of the trading process, an improvement possible only by considering the securities market function as the joint evolution of a set of variables mutually and globally correlated.

\section{References}

Chemmanur, T. (1989, May). The pricing of initial public offerings: a dynamic model with information production. Salomon Brothers Center for the Study of Financial Institutions, Leonard N. Stern School of Business, New York University, working paper series, 521.

Fama, E. (1976). Foundation of finance. New York, Basic Book Inc. Publishers.

Fusconi, A. (1991). Economia e tecnica del mercato finanziario e mobiliare (The Economics and techniques of the 
financial market). Torino, Giappichelli Editore.

Grossman, S., \& Stiglitz, J. (1980, June). On the impossibility of informationally efficient markets. American Economic Review, 70(3), 393-408.

King, M., \& Roell, A. (1988). Insider Trading. Economic Policy, 7, 163-193. https://doi.org/10.2307/1344507

Leland, H. E. (1990, March). Insider Trading: should it be prohibited?. Institute of Business and Economic Research, University of California at Berkeley, Finance working paper, 195.

Leland, H. E., \& Pyle, D. H. (1977, May). Informational asymmetries, financial structure and financial intermediation. The Journal of Finance, 32(2), 371-387. https://doi.org/10.2307/2326770

Manne, H. (1966). Insider trading and the stock market, New York, Free Press.

Meulbroek, L. K. (1992, December). An Empirical Analysis of Illegal Insider Trading. The Journal of Finance, 47(5), 1661-1699. https://doi.org/10.1111/j.1540-6261.1992.tb04679.x

Portale, G. (1989). La disciplina dell'insider trading nella Repubblica federale di Germania (The insider trading discipline in the Federal Republic of Germany). Banca Borsa e Titoli di Credito, LII(II), Milano, Giuffrè.

\section{Notes}

Note 1. Directive 2003/6/CE, transposed in Italian Law in 2005, is the first systematic legislation at a European level related to market abuse; followed by the 20014/57/CE directive which changed administrative and penal sanctions (in Italy it was transposed in July 2016).

Note 2. The distinction between institutional and temporary insiders, which has been specified by the directives, comes into play here. The institutional insiders can be identified as those subjects that by their nature have access to privileged information (partners, administrators, etc.). According to article 115.bis of the Consolidated Law on Finance these subjects are required to establish a register to be kept regularly updated by the listed issuers and the controlled "bodies". Temporary insiders - also referred to as tippee - are identified as those subjects who do not have a direct access to privileged information, but come to access it in a mediated way for they receive it from a primary insider (or as a result of illegal activity).

Note 3. Represented in Italy by Law n. 157/1991 and the following transpositions of the EU Directives. 